\title{
Core. Sobre enfermos, enfermedades y la búsqueda del alma de la medicina de Andrzej Szczeklik. Un caso de hibridación de géneros*
}

\author{
Kore. On Sickness, the Sick and the Search for Soul in Medicine, \\ by Andrzej Szczeklik. A case of hybridization of genres
}

ABSTRACT: This paper deals with the genre of Andrzej Szczeklik's second work, Kore. On Sickness, the Sick and the Search for Soul in Medicine. Marketed as a science popularization book that aims to bridge the gap between science and art, this work is indeed, from a rhetorical point of view, a hybridized rhetorical discourse mixing two different genres such as essay and homiletic genre (according to A. W. Halsall's rhetorical genres theory).

Keywords: genre theory, rhetorical genres, hybrid genres.

RESUMEN: En este artículo se reflexiona sobre el género del segundo libro de Andrzej Szczeklik, titulado Core. Sobre enfermos, enfermedades y la búsqueda del alma de la medicina. Vendido al público como un ensayo de divulgación científica que tiende un puente entre la ciencia y el arte, el análisis que realizamos nos permite responder que estamos ante un discurso retórico que hibrida dos géneros, el homilético y el ensayo erudito, según la clasificación de géneros retóricos ofrecida por A. W. Halsall.

Palabras clave: teoría de géneros, géneros retóricos, géneros híbridos.

(*) Trabajo realizado en el marco del proyecto ministerial de investigación «Retórica constructivista: discursos de la identidad» (FFI2013-40934-R). 


\section{1. ¿Quién era Andrzej Szczeklik? Un marco necesario}

Andrzej Szczeklik (1938 - 2012) fue un médico polaco, profesor y presidente del Departamento de Medicina en la Facultad de Medicina de la Universidad Jagellónica (Collegium Medicum) en Cracovia, con importantes investigaciones en enfermedades cardiopulmonares, en el asma inducida por la aspirina y en los mediadores químicos para las enfermedades del sistema circulatorio y respiratorio. Fue además mecenas y amigo de artistas y se hizo famoso por sus improvisados conciertos de piano en el cabaret Piwnica pod Baranami. También publicó dos libros de gran éxito, muy bien recibidos por la crítica y traducidos al inglés, al húngaro y más recientemente al español: Catarsis. Sobre el poder curativo de la naturaleza y el arte (2002 [castellano, 2010]) y, posteriormente, el que va a ser objeto de este trabajo Core. Sobre enfermos, enfermedades y la búsqueda del alma de la medicina (2007 [castellano, 2012]).

En El País del 5 de abril de 2010 podemos leer en la sección de cultura y con motivo de la publicación de Catarsis:

Con la eutanasia y la biogenética, no transige, quizá por ser miembro de la Academia Pontificia de las Ciencias del Vaticano. «Soy católico, tengo unas creencias por las que soy absolutamente contrario a alterar el proceso de un embrión; ¿hasta dónde podemos intervenir en la creación?; quizá valga la pena recordar que también hay límites, como Zeus y Asclepio». ${ }^{1}$

La noticia de la publicación del libro la dio de esta manera Diario Médico.com:

El médico, humanista, músico, mecenas, dirigente del sindicato Solidaridad y amigo de Juan Pablo II, Andrzej Szczeklik, acaba de publicar el libro $\mathrm{Ca}$ tarsis (Ed. Acantilado). ${ }^{2}$

Se haría difícil entender estas dos publicaciones de Andrzej Szczeklik, $\mathrm{Ca}$ tarsis y Core, y muy especialmente la segunda, sin atender a su fe católica, un catolicismo además de raigambre polaca, y a su resistencia al régimen marxista de su país. Ese marco ideológico del que bebe el autor, científico católico y

1. http://cultura.elpais.com/cultura/2010/04/05/actualidad/1270418404_850215.html (17 de febrero de 2014).

2. http://www.diariomedico.com/2010/03/15/entrevistas/entrevistas-de-ultima/fuera-deconsulta/hay-espacio-para-el-arte-en-la-medicina (17 de febrero de 2014). 
culto, alimenta, mayoritariamente, la abrumadora serie de referencias culturales del universo de su erudición humanística. Y hasta en ocasiones podemos constatar que ciertas referencias que no están directamente relacionadas con su ideología sin embargo las saca, de manera indirecta, del ámbito de autores de su cercanía ideológica. Es fácil hacer el mapa de sus lecturas, pues no oculta en ningún momento las terceras vías. Esto no quita ni un ápice a su erudición, que se fortalece con el trato cercano de grandes personalidades de las letras y las artes polacas, en un momento crucial que describe así Ángel Enrique DíazPintado Hilario en su tesis doctoral sobre el poeta, novelista y ensayista polaco Adam Zagajewski:

[...] llegamos a los años ochenta, período -como es bien sabido - de intensos conflictos sociales y de profundos cambios políticos en Polonia [...]. El surgimiento del histórico sindicato Solidaridad (Solidarność), liderado por Lech Wałęsa (Premio Nobel de la Paz en 1983) marcó el principio del fin de la dictadura comunista y del triunfo de las fuerzas democráticas en Polonia. Ni que decir tiene, estos acontecimientos tienen también su reflejo en la lírica polaca de aquellos años.

Un acontecimiento -éste de índole propiamente literaria - que tuvo entonces un especial significado para la poesía y las letras polacas en general fue la concesión en 1980 del Premio Nobel de Literatura a Czesław Miłosz, galardón que tres lustros más tarde, en 1996, recibiría la poetisa Wisława Szymborska. ${ }^{3}$

La relación entre el fin de la dictadura comunista y el florecimiento de las artes en Polonia tiene en los libros de Andrzej Szczeklik un perfecto correlato en la relación que establece entre arte, literatura y alma humana, por encima de los aportes de la medicina. No en balde aparece en Core recurrentemente la relación personal de Szczeklik con Miłosz.

\section{2. ¿Qué es Core. Sobre enfermos, enfermedades y la búsqueda del alma de la medicina? Una dilucidación genérica que pasa por la retórica y la hibridación}

Vendido al público europeo como un ensayo humanístico, una especie de continuación del pensamiento que se plantea en Catarsis, este libro de Szczklik

3. http://hera.ugr.es/tesisugr/21008693.pdf\#page=1\&zoom=auto,0,375 (17 de febrero de 2014). 
sigue proponiendo que sabemos más del alma humana desde la historia de la literatura y el arte que desde los estudios médicos. En principio, un planteamiento de este tipo, en un mundo tecnológico (más que científico), en un tiempo de pragmatismo feroz y en el que los valores más que nunca se rigen por el materialista adagio del tanto tienes tanto vales, parece una bocanada de aire fresco.

Al afrontar un análisis del libro, nuestra primera cuestión es una pregunta de género: ¿En realidad ante qué estamos, realmente ante un ensayo humanista hecho por un médico, ante un tratado de divulgación científica con gran erudición literaria? La respuesta que nosotros damos no la vamos a dilatar por más tiempo y es la siguiente: estamos ante un discurso retórico que participa de dos géneros, el homilético y el ensayo erudito.

Será conveniente aclarar qué es el género homilético y también por qué consideramos el ensayo erudito como un género retórico. Siguiendo a Halsall (1998: 270) en la ampliación que hace de la tabla que en su prontuario de la retórica antigua había ofrecido Barthes (1990: 141), podemos aumentar el esquema de los géneros aristotélico hasta llegar a un número de cinco. Así, además del demostrativo, deliberativo y judicial, existiría un cuarto género, el género homilético, correspondiente a la retórica de los sermones, que fue añadido durante la Edad Media y tuvo gran auge durante el Barroco (pensemos en el mundo de Fray Gerundio de Campazas), y en quinta posición estaría el ensayo erudito, bien sea literario o no, donde entran los discursos de tesis doctoral, o los ejercicios de oposición en el ámbito español. Por tanto, el esquema tripartito inicial quedaría ampliado de la siguiente manera (Pujante, 2003: 84):

\begin{tabular}{ll}
\hline GÉNERO & $\begin{array}{l}\text { Tipo de participación del auditorio: Como espectador. } \\
\text { Tiempo aludido: principalmente presente. } \\
\text { Objeto discursivo: estético-moral. } \\
\text { Finalidad: conmover sobre lo honroso/feo. }\end{array}$ \\
\hline GÉNERO & Tipo de participación del auditorio: Como árbitro. \\
DELIBERATIVO & $\begin{array}{l}\text { Tiempo aludido: futuro. } \\
\text { Objeto discursivo: lo que puede suceder o no. } \\
\text { Finalidad: persuadir sobre lo útil/dañoso. }\end{array}$ \\
\hline
\end{tabular}




\begin{tabular}{ll}
\hline GÉNERO JUDICIAL & $\begin{array}{l}\text { Tipo de participación del auditorio: Como árbitro. } \\
\text { Tiempo aludido: pasado. } \\
\text { Objeto discursivo: acción cometida llevada ante un } \\
\text { tribunal. } \\
\text { Finalidad: persuadir sobre lo justo/injusto. }\end{array}$ \\
\hline GÉNERO HOMILÉTICO & $\begin{array}{l}\text { Tipo de participación del auditorio: Como congrega- } \\
\text { ción de creyentes. } \\
\text { Tiempo aludido: pasado/presente/futuro. } \\
\text { Objeto discursivo: virtud/vicio. } \\
\text { Finalidad: exhortar/condenar. }\end{array}$ \\
\hline $\begin{array}{l}\text { ENSAYO ERUDITO/ } \\
\text { ARTÍCULOS/ }\end{array}$ & $\begin{array}{l}\text { Tipo de participación del auditorio: Conjunto de profe- } \\
\text { sores como árbitros. } \\
\text { Tiempo aludido: } \text { pasado/presente/futuro. } \\
\text { OPOSICIÓN }\end{array}$ \\
\hline $\begin{array}{l}\text { Objeto discursivo: intra- e interdisciplinar. } \\
\text { Finalidad: probar la competencia profesional. }\end{array}$ \\
\hline
\end{tabular}

Si bien será fácil aceptar que este trabajo de Szczeklik es un ensayo (en principio un ensayo de medicina como su nombre indica, Core. Sobre enfermos, enfermedades y la búsqueda del alma de la medicina, con carácter divulgativo), se hace necesario mostrar por qué consideramos que este ensayo es un género retórico y por qué, bajo el género más evidente, más fácilmente observable, se encuentra un discurso homilético. Es más, el carácter divulgativo del ensayo está en relación directa con el carácter homilético de su discurso. En suma, este ensayo de Szczeklik es un peculiar ejemplo de hibridación de géneros retóricos en el esquema ampliado de Halsall.

Creo que Halsall nunca hubiera pensado en incluir entre los géneros retóricos el ensayo tal y como lo entendemos en su caracterización primaria, en los ensayos de Montaigne, dado que su subjetivismo lo alejaba de la finalidad persuasivo-social y lo acercaba a los géneros literarios. Sin embargo, el ensayo pronto evolucionó a género argumentativo no prototípicamente literario y con una frontera polémica con lo literario. ${ }^{4}$ La teoría de la prototipicidad permite hablar de conjuntos en los que hay grupos de elementos que son prototípicos de

4. Ya G. Lukács en El alma y las formas habla del lugar especial que merece el ensayo en el estudio de los géneros (Lukács, 1975: 15-39). 
esos conjuntos, por ser los que los caracterizan y definen; junto a los que hay otros elementos no prototípicos, también miembros del conjunto, pero que no lo definen o caracterizan. Según esto, la épica, la lírica y la dramática son los prototípicos representantes del conjunto de géneros literarios. El género argumentativo estaría, en cambio, situado en la periferia, sería género no prototípicamente literario. De inmediato todos pensamos en los ensayos de Ortega y Gasset, Eugenio D’Ors o de Marañón.

Cuando hablamos del ensayo hoy en día nos vemos obligados a ampliar el campo y hablar de género argumentativo, como troncal, lo que además nos permite acercarnos más a la relación con lo retórico. Porque ciertamente al hablar de género argumentativo hemos de partir de la existencia de textos pertenecientes al género argumentativo sin carácter literario. En la base de su caracterización como género se encuentra un macroacto de habla perlocutivo por el que el receptor modifica pensamiento o actuación (Searle, 1980). El componente didáctico (docere) puede darse en otros géneros, pero aquí es básico.

Dentro de este género, por tanto, y más allá del ensayo, se pueden incluir variadas manifestaciones como los discursos retóricos o las obras de historia con carácter literario - como las obras de Heródoto, Tácito, y, más recientemente, Burckhardt y Mommsen-, también los diálogos, de tan espléndida factura en el Renacimiento, las epístolas -sin que se incluya aquí el género epistolar poético, pero sí toda esa correspondencia entre filósofos, literatos y artistas, políticos o intelectuales que sobrepasan la circunstancialidad del texto epístolar, por su trascendencia temática o artística-; también pueden adscribirse las biografías y los libros de memorias, al igual que los diarios -piénsese en diarios tan importantes como los de Thomas Mann o André Gide-, o los libros de viajes, con ejemplos tan sobresalientes como los de Chateaubriand, Beckford y Burton.

Volviendo al ensayo, como un componente del género argumentativo, en concreto el ensayo que prueba la competencia profesional (y aquí entraría también cultural en un más amplio sentido) del autor, que participa de lo propio de la disciplina pero también queda fuera, nos permite matizar lo que Halsall llama ensayo erudito (entendiéndolo él como ensayo especializado), de una manera laxa e incluir en esa denominación el ensayo de erudición, con elementos del ensayo para especialistas y a su vez con un aspecto divulgativo que permite un auditorio más amplio. Sin duda esta caracterización está más acorde con los principios de la retórica, que en ningún caso excluye públicos por falta de preparación especial (los receptores de un discurso retórico jamás pasan por ningún tamiz de selección, de exclusión), y además esta redefinición laxa del apartado de Halsall (que incluye el ensayo erudito / el artículo académico / la 
tesis / el ejercicio de oposición) se adecua perfectamente al ensayo objeto de nuestro estudio.

\section{La narratio del discurso de Core. La construcción narrativa como constructora de argumentación}

En la actual investigación sobre el discurso existe una fascinación por la narrativa que, como indica Alexandra Georgakopoulou (2011: 191), no es otra cosa que una recuperación y revitalización de la teoría de la narratio retórica. La teoría narrativa desarrollada en la tradición retórica puede aparecer hoy ante nosotros como una especie de pre-género o meta-género discursivo. La narratio o exposición, en sus orígenes, es la segunda de las partes del discurso retórico (diégesis para los griegos, una especie de la genérica próthesis), y sigue al exordio y precede a la argumentación. En general, en todo discurso, la narración es la exposición de los hechos en coherencia interpretativa. Cómo vemos lo que vemos desde el lugar que lo vemos. Visión personal, perspectiva e interpretación son elementos básicos de toda narratio sobre aspectos del vivir que intentamos comprender. Luego, esa propuesta narrativa hay que argumentarla.

Las leyes de la narratio retórica han constituido un importante venero para los estudiosos de los procedimientos narrativos de la literatura, de la misma manera que el estudio pormenorizado de los tropos y las figuras retóricas han servido para fundamentar la teoría del lenguaje literario. Podríamos decir que tanto en el nivel estructural como en el nivel elocutivo los planteamientos retóricos han sido la base, el tronco de cuanto ha venido después, así en el discurso literario como en el discurso social comunicativo sin aspiraciones literarias.

La tradición retórica nos ofrece una tipología narrativa que sigue teniendo vigencia. Cicerón quizás sea de los que mejor hacen la clasificación. Considera que hay tres tipos de narración: La primera incluye la propia causa y el estado de la controversia (Cicerón, De invent. 1 19). Es una descripción del estado de la causa del discurso. Como hemos dicho ya, la narración nos obliga a exponer todo lo que constituye el fundamento de la argumentación que seguirá. Exponemos cómo creemos que son las cosas, para luego argumentarlo. Esta es la narratio retórica propiamente dicha. La segunda clase de narración de la que habla Cicerón contiene una digresión externa a la causa y tiene como finalidad acusar, comparar, divertir de manera acorde con el tema que se discute o amplificar (Cicerón, De invent. 1 19). Es un excurso o digresión, que puede aparecer en cualquier parte o momento del discurso. Por cierto, Szczeklik re- 
curre mucho a esta segunda narratio, generalmente con carácter de ejemplo y poder argumentativo: bien sobre hechos inventados (utiliza ejemplos literarios, ejemplos mitológicos, ejemplos pictóricos, etc.), bien sobre hechos sucedidos (anécdotas de su vida personal y profesional). La tercera clase de narración ciceroniana es ajena a las causas civiles; su único objetivo es agradar pero sirve también como útil ejercicio para adiestrarse en el hablar y en el escribir (Cicerón, De invent. 1 19). Es la narración literaria, que corresponde principalmente al arte poética pero que es muy útil al arte retórica. Con la evolución de la cultura occidental podemos decir que se mezclaron indisolublemente narratio retórica y narratio literaria. En el caso del ensayo que nos ocupa, podemos decir que esa confusión permanece y se fortalece, pues a través de un artefacto con bastantes elementos literarios, como es Core, se nos ofrece un discurso persuasivo, además de carácter doctrinal, puesto que pretende exhortar a que nos olvidemos de todos los hallazgos de los tiempos de la biología molecular, cuyos conocimientos no son sino «un fragmento minúsculo de un misterio que solo Dios conoce al completo» (Szczeklik, 2012: 302). Quizás podríamos resumir toda la intención doctrinal del libro, la razón persuasiva de las diferentes estrategias narrativas que lo constituyen, en las palabras que acabamos de transcribir.

El reciente interés por la narratio que han mostrado los estudiosos del discurso desde el ámbito propiamente lingüístico pero especialmente relacionado con los estudios antropológicos y otras disciplinas, aporta a la sólida teoría narrativa de la tradición retórica importantes matices que son muy rentables a la hora de tratar el discurso de Andrzej Szczeklik. Nos interesa especialmente el hincapié que se hace en la relación que tienen ciertos procedimientos estructurales de las narrativas con la argumentación. De esta manera, la tradicional división entre narratio y argumentatio queda diluida, y se considera que la propia construcción narrativa es constructora de argumentación. Así, Elinor Ochs (2000) subraya ( $\sin$ que sea total novedad, pues sigue a Heidegger y a Ricoeur) que el tiempo de la narración no es un tiempo cronológico sino un tiempo humano. Es decir, la organización narrativa de hechos pasados o futuros, reales o hipotéticos, no es sino un instrumento para dotar de significado a la experiencia del tiempo presente y las expectativas del futuro. Ochs propone, por tanto, comprender los géneros narrativos no tanto como tipos de texto, sino como perspectivas sobre un discurso que construye un acontecimiento social (Ochs, 2000: 282).

En el caso del discurso que nos ocupa es evidente que la naturaleza de la narración está ligada plenamente a la naturaleza de la cultura del propio narrador y que toda la narrativa discursiva se construye con una serie de referencias culturales que organiza persuasivamente hacia la idea fundamental que intenta 
inocular en el lector: la insuficiencia de la ciencia para aplacar la inquietud profunda de todo ser humano respecto a su razón de ser en este mundo.

El autor, con gran sutileza, propia de su amplia cultura, crea un entramado de referencias, a veces simplemente acumulativas (pero no debemos desestimar el poder de la acumulación, que es un importante procedimiento figural), ${ }^{5}$ que procura solidificar una identidad cultural, la identidad del narrador, identidad que ofrece al lector como acto comulgatorio. En dicho entramado se manifiesta una interdiscursividad que nos obliga a referir con Albaladejo «la dimensión cultural de la Retórica» (Albaladejo, 2013). Esta retórica cultural se ocupa de la construcción cultural de los discursos, de su producción desde y en conexión con la configuración cultural de la sociedad. A nosotros nos interesa especialmente ver esta red interdiscursiva como productora de identidad cultural y como argumentadora de ideas culturales que llevan a esa identificación. Es el planteamiento de Hayden White (1980: 5) y Jerome Bruner (1991).

Hayden White (1980: 27) afirma que toda narrativa (ficción narrativa, relato histórico o científico pretendidamente objetivo) incorpora necesariamente una valoración moral de los hechos narrados, y Elinor Ochs recupera esta idea desde el enfoque de los estudios del discurso cuando, a propósito de la narración de experiencias vitales, afirma que

como las narraciones tienen por lo menos un punto de vista, por su naturaleza misma formulan juicios. [...] Muy a menudo, los relatos son vehículos que colaboran en la enseñanza de los valores morales de una familia, de una institución pública $[\ldots]$ o de una comunidad en general. Los mensajes sobre la verdad y la moralidad contribuyen a las explicaciones causales que las narraciones normalmente construyen. (Ochs, 2000: 295)

\section{Análisis de Core de Andrzej Szczeklik siguiendo los presupuestos anteriormente desarrollados. Los elementos de especial expresividad discursiva: la estructura narrativa y la erudición elocutiva como argumentación}

La argumentación, que en un tratado científico se limita a los sistemas matemáticos, físicos o biofísicos propios del paradigma científico, así como a los procedimientos y métodos experimentales; en el discurso ensayístico, hibridado con el género homilético, que se da en Core tiene una sólida base

5. Cf. David Pujante, Manual de retórica, cit., pp. 239 y ss. 
en aspectos emocionales, en relación directa con las dóxai (opiniones) sociales, que no caben, sin embargo, en la expresión científica. En este ensayo, los ejemplos abundantes, las referencias cultas acumulativas, los poemas referidos, los cuadros, los mitos, etc., cumplen la retoricidad argumentativa, es decir, configuran una argumentación que se interseca con las narraciones que lo componen. Porque, lo mismo que en Core no nos encontramos con la totalidad de las partes que caracterizan al discurso retórico (dado que no es necesario, por ejemplo, que haya un exordio, pues todo lector que elige leer el libro anula con su gesto la necesidad de despertarle el interés discursivo, propio de un discurso oral), tampoco nos encontramos en este ensayo con la clara delimitación tradicional entre narratio y argumentatio, dándose que, como ya hemos avanzado, la propia construcción narrativa es constructora de argumentación.

En la tradición retórica, la narración comparte el fin general del discurso que es persuadir, pero su finalidad específica es enseñar o instruir (docere) al oyente sobre el asunto traído a controversia, como indica, entre otros, Quintiliano (Inst. orat. IV 2 31). Para conseguirlo hay que ayudarse del delectare (hay que enseñar distrayendo) y del movere (mientras se informa hay que conmover al receptor del discurso). En el caso del libro sobre el que estamos reflexionando los aspectos del delectare y del movere constituyen un elemento básico que lo convierten, en el primero de los casos, en un tratado divulgativo de los progresos de la ciencia, y en el segundo, en un discurso homilético que trata de exhortarnos a seguir creyendo en Dios.

El delectare ('deleitar', 'agradar') incluye el conjunto de recursos de expresividad especial, no necesariamente literarios, que refuerzan un discurso. Hablamos de una finalidad discursiva que cobra especial protagonismo cuando hay intención divulgativa, cuando el texto discursivo va dirigido a un público no especialista, como en el texto que estudiamos. En él, un médico prestigioso nos ofrece su experiencia personal, sus conocimientos de la historia de la medicina y su posicionamiento emocional e ideológico (religioso y político) en un ensayo lleno de referencias literarias, artísticas, filosóficas, musicales, pictóricas.

Los recursos de expresividad están presentes en todo discurso, no son exclusivos de los textos literarios (componente estético) o de los textos divulgativos (componente de agrado necesario al neófito, como al niño el buen sabor de la medicina). Sin embargo, podemos considerar que hay un claro aumento cuantitativo de esa expresividad en el recorrido de la dirección que nos lleva desde los discursos científicos (para especialistas) hacia los discursos de persuasión social (para el ciudadano en general) y finalmente a los discursos literarios (para el degustador de la literatura). El texto que nos ocupa tiene una intención comunicativo-divulgativa de temas propios de la medicina, y asume 
un componente de construcción literaria que es evidente también a lo largo de todo el ensayo. Por tanto, la finalidad delectativa responde tanto a razones retóricas (deleitar enseñando) como a razones puramente estéticas.

Los niveles en los que estos recursos de expresividad especial aparecen son principalmente el nivel estructural: las narrativas del ensayo, y el nivel elocutivo: el conjunto de recursos tropológicos y figurales del texto. Lo especialmente interesante es cómo esos recursos de expresividad se ponen al servicio de la argumentación.

Desde el punto de vista estructural podemos fijarnos, al leer el texto, en cómo utiliza el autor la segunda narratio de Cicerón como recurso expresivo y delectativo para contarnos, en sucesivos ejemplos sobre hechos reales o imaginarios, lo que podría ser un tedioso capítulo de historia de la medicina. Así, por ejemplo, en los comienzos del libro, el capítulo titulado «El cerebro» cuenta la evolución del pensamiento sobre el funcionamiento del cerebro a través de una serie de historias, bien personales bien provenientes de la historia de la medicina, que nos conducen con gran maestría literaria hasta el momento actual, donde nos muestra la complejidad del pensamiento médico al respecto (Szczeklik, 2012: 63) y la dificultad de dilucidar las verdades profundas del ser humano a pesar de los avances científicos: la difícil relación entre cerebro y alma humana, el problema de decidir si las neurosis surgen por influencias culturales o por costumbres sociales o bien por razones de mecánica cerebral. Entonces es el momento en el que comprendemos que todos los ejemplos que ha utilizado el autor en su relación tienen peso argumentativo. Suele ser una tónica general del libro la de emplear un ejemplo como elemento que apoya argumentativamente el relato, o cada aseveración del relato, siguiendo un esquema sencillo: «proposición + relato ilustrativo».

En el capítulo «En busca del alma» el modo de poner ilustraciones ejemplificadores (sin pretender que sean ejemplos prueba) resulta muy eficaz retóricamente: persuade al lector neutralizando la sensación dogmática, de imposición de un pensamiento determinado, que en este caso es el pensamiento católico más conservador. El autor no muestra en ningún momento una argumentación de probatoria fuerte; va sugiriendo, trayendo ejemplos ilustrativos, narrando experiencias (como la de Pascal). En ningún momento el discurso se muestra como una argumentación probatoria, rígida, que podría provocar el rechazo del lector. Remitimos a la distinción de Perelman y Olbrechts-Tyteca (1989: 546 ss.) entre ejemplo, ilustración y modelo.

No se narra histórica o cronológicamente, pues se destacan algunos fenómenos de otros, creando un tiempo muy marcadamente personal. La temporalidad subjetiva enraíza mejor el entramado argumental por medio de ejemplos. Esto nos 
recuerda a Jerome Bruner (1991) que subraya el trasfondo cultural que subyace en cada uno de los rasgos que caracterizan la narrativa, entre los que se encuentran las convenciones que determinan el modo de representar la temporalidad.

Es imprescindible hablar de la interdiscursividad en este ensayo, dado que recurre constantemente al injerto de otros discursos. Consideremos de nuevo el capítulo seminal titulado «En busca del alma». Hay en él toda una red de citas y referencias, trenzadas entre sí: Homero lo lleva a Calasso, luego a Frazer, nuevamente a Homero, pasa a Apuleyo, a los pitagóricos, al mito de Orfeo para saltar a Rohde y Dodds. En suma, toda una red de citas de poetas, filósofos, eruditos para construir la autoridad del pensamiento que el autor quiere ofrecernos: la persona se encuentra con su alma a través del arte. El autor diferencia así dos tipos de enfermedades: «Si el mal se encuentre en el alma, es el arte el que trae la catarsis; si está en una enfermedad del cuerpo, entonces la sanadora es la medicina» (Szczeklik, 2012: 73).

Siempre solidifica una identidad cultural, una identidad ideológica, por acumulación de referencias, construyéndola sobre citas enlazadas de unos con otros autores, que en un alto porcentaje son de la cultura polaca y del ámbito ideológico del propio autor: la poeta Gorbawiewska, el mitólogo Parandowski, etc. Tanto es así que muchas de las referencias clásicas le vienen intermediadas por este ámbito cultural, y no lo oculta en ningún momento, pues da las referencias a través de sus fuentes secundarias. Quizás el mejor ejemplo de esta intermediación sea el momento en el que debe apuntalar, a través de la tradición mitológica antigua, la imagen del alma humana como Kore, la muñequita visible a través de la pupila. Es la idea básica de todo el libro y la que le da título. Pues bien, después de una serie de referencias a los egipcios, a los griegos, a la posible etimología del término, a la posible relación que tiene con el mito de Perséfone (a la que el autor solo llama Core); en suma, después de todo este despliegue de erudición, acaba diciendo:

No es fácil encontrar en las fuentes escritas griegas o romanas, incluidos los textos médicos, un registro exacto de este punto de vista, que defendió entre otros Jan Parandowski, consistente en que la «muñequita» que aparecía en la pupila no era otra cosa que el alma personificada. (Szczeklik, 2012: 78)

Precisamente el perfil de este profesor y ensayista polaco, Jan Parandowski, conocido en Polonia por sus trabajos sobre la Antigüedad clásica, es una vez más un perfil de intelectual católico y humanista, miembro de 1945 a 1950 del Departamento de Antigüedad Clásica en la Universidad Católica de Lublin, institución en la que en 1976 recibió un doctorado honoris causa en Filosofía Cristiana. 
El capítulo titulado «Reflejos del mundo que llevamos dentro» se ocupa de relativizar la sintomatología de las enfermedades, considerando que hay cambios en las enfermedades que dependen de los pacientes. Igualmente considera que los hallazgos científicos en el terreno de la medicina, como en otros ámbitos, están en relación con elementos emocionales (Szczeklik, 2012: 120). La idea básica del capítulo es que todo está en nuestro interior y de ahí surgen las grandes intuiciones científicas. Llegado a este punto, el de las intuiciones humanas, considera que muchas de estas intuiciones las han tenido los poetas antes que los científicos llegaran a ellas, y recurre a Rilke y a Milosz para ejemplificarlo (Szczeklik, 2012: 121). Una vez más recurre a su propia experiencia como médico, que combina con su cultura filosófica y literaria. De nuevo esta interdiscursividad, a la que ya nos hemos referido y que se construye a base de injertos culturales, de selecciones personales, crea la solidez narrativa en la que se reinstala permanentemente su identidad de polaco culto, médico y literato, creyente católico, una identidad que ofrece sutilmente al lector como identidad cultural generalmente aceptable. Es lo que configura el carácter homilético del discurso de Szczeklik.

Este carácter homilético del discurso de Szczeklik no tiene por qué conducirnos a un rechazo de su experiencia, de su humanidad, de su reivindicación de los aspectos más humanos en la relación médico-paciente, de la importancia de la atención a la cultura para reinterpretar los problemas de siempre, de la necesidad de volvernos a instalar más acá de lo puramente científico o técnico, más acá del ensoberbecido comportamiento de la humanidad en los últimos lustros, como si hubiéramos sido capaces de iluminar todos los rincones del misterio. Este volver al humanismo desde la comprensión de todo lo que nos queda por saber, posiblemente sea el más goloso de los ofrecimientos de este ensayo y en concreto el que a mí más me gusta e interesa. Pero por ese camino también podemos caer, y con más facilidad y con más ingenuidad, en la propuesta más dogmática del libro. Su hibridismo, entre ensayo erudito y discurso homilético, es la clave de su peligro intelectual; pues como ensayo erudito pretende probar la competencia profesional de su autor a la hora de decidir sobre los asuntos que trata, pero resulta que esos asuntos acaban yendo más allá del objeto discursivo de un ensayo erudito y entran en el objeto de la virtud y en la finalidad de la exhortación. Szczeklik incorpora en su visión del mundo un muy alto porcentaje de valoración moral. Vemos en este ejemplo del libro de Szczeklik que las narrativas no son un simple objeto discursivo, un texto, sino que al mismo tiempo son una práctica social comunicativa con una fuerte impregnación de valores culturales. Por muy pretendidamente objetivas que sean, 
incorporan una valoración moral de los hechos que se narran. Recordemos de nuevo la referencia de Elinor Ochs al respecto (Ochs, 2000: 295).

Uno de los puntos clave del pensamiento de Szczeklik es el parentesco entre arte y medicina, en cuanto medios sanadores ambos: el uno del alma, el otro del cuerpo. "Si el mal se encuentra en el alma, es el arte el que trae la catarsis; si está en una enfermedad del cuerpo, entonces la sanadora es la medicina» (Szczeklik, 2012: 73). Más adelante retoma la idea, ofreciéndonos lo que él considera el tronco común: «la magia, tronco común a partir del que se desarrollaron tanto la medicina como el arte» (Szczeklik, 2012: 124). La magia, sustentada en la omnipotencia de la palabra, con sus fórmulas debidamente pronunciadas, traía la salud o la muerte, la sequía o la lluvia, evocaba a los espíritus y revelaba el porvenir. Es una idea que ya aparecía en su primer libro, Catarsis (Szczeklik, 2010: 23). Primero fue el arte de la palabra y después vino el arte del comprender (Szczeklik, 2012: 124). Pero para Szczeklik la magia representa también la aparición del milagro, y la fe en la palabra, y de inmediato trasforma la idea en un alegato sordo pero contundente a favor de la fe religiosa, de la fe en la palabra sagrada, por encima de la comprensión. En este mismo capítulo avanza un poco más en esa línea cuando habla de la sensibilidad ante el sufrimiento humano, una vez más convirtiéndolo en virtud aparentemente exclusiva del creyente, aunque no lo explicite: «Es necesario cuidar esa sensibilidad que hay en nosotros, la sensibilidad del corazón. Se habla poco de ello, puesto que se espera que sobre todo los artistas sean sensibles; quizás los vínculos entre la medicina y el arte queden claros también en ese plano» (Szczeklik, 2012: 131). Si no hubiera tan claramente una homilética en estas palabras, quedarían en un alegato humanista. Como cuando dice más adelante:

Hubo una vez un tiempo, del que nos separan doscientos años, en que la biología, la ciencia y el arte -al igual que las observaciones y especulaciones sobre la naturaleza- estaban entretejidas con hilos tan fuertes que resultaba difícil distinguir unas de otras. (Szczeklik, 2012: 159)

Pero todo el final del largo capítulo está sembrado de dudas respecto a los principios universales de la ciencia actual, dudas sobre sus discursos cambiantes (los diferentes conceptos de la física de partículas en los últimos decenios: partículas elementales, quarks, etc.), sobre el reduccionismo que representa comprender el mundo dividiéndolo, $\mathrm{y}$, sobre todo, está impregnado de su lucha personal contra el darwinismo, para así consolidar la idea final del capítulo: hay que volver a los modelos universalistas porque le dan cuello al creacionismo y al plan universal, naturalmente de Dios. De esta manera toda 
la magnificencia del desarrollo de un pensamiento en dinámica, en complejidad, en acción (lo que podemos considerar el ensayo erudito moviéndose en los límites del conocer científico), se achica, se estrecha en lo doctrinal (en lo homilético). Pero lo hace con una gran sutileza e inteligencia, lo pone en boca de los contados críticos del evolucionismo: «Hay que añadir que esos puntos de vista tan originales son aislados y al romper los esquemas generalizados de los evolucionista, reciben críticas por tener tintes de creacionismo» (Szczeklik, 2012: 162).

El capítulo siguiente, «Genética y tumores», que una vez más se inicia con una serie de referencias literarias (Brodsky, Kafka, Hardy) se centra en el problema de saber qué es lo permanente, lo que sobrevive del ser humano. Una vez más considera que la literatura y el arte ya han contestado. A ese saber profundo, ancestral, verdadero, que nos llega a través del arte, opone los discursos de la ciencia, cuyas ideas prescriben, acaban siempre trasnochadas. Vuelve a su procedimiento narrativo habitual: junto a las citas cultas aparece una serie de ejemplos, en esta ocasión ejemplos de descubrimientos sobre genética que acaban desechándose, incluido el concepto de gen. Son construcciones discursivas que hay que ir renovando con los nuevos hallazgos. El aparentemente fascinante conocimiento del genoma humano no ha conseguido una paralela fascinante aplicación a las enfermedades. Toda esta visión constructivista, aparentemente muy novedosa, deja de serlo en el momento que se hace parcial, pues aplica ese constructivismo a los discursos científicos pero deja fuera los discursos del arte, como discursos especiales, de alta verdad, como discursos chamánicos.

En el centro del libro nos encontramos con el capítulo «Verdades biológicas y fe». En este capítulo (que comienza con una nueva crítica al darwinismo desde el principio, contrario, del altruismo humano, inexplicable en el mundo diseñado por Darwin), finalmente el autor decide dejar clara su postura de hombre de fe y procura separarla de la ciencia (Szczeklik, 2012: 209). Habla de dos conocimientos, el de la razón y el de la fe (emocional) (Szczeklik, 2012: 210) y acaba diciendo: «la razón ilumina el mundo en el que existimos, mientras la fe lo dota de sentido» (Szczeklik, 2012: 211).

Es en este momento central cuando el ensayo se vuelve homilético de manera explícita, sin ambages. $Y$ acaba recurriendo al principio de autoridad religiosa, que para él es el papa Juan Pablo II. También se apoya en el filósofo Leszek Kołakowski, un importante filósofo polaco contemporáneo, especialmente interesado en las teorías filosóficas y teológicas que subyacen en la civilización occidental. Un perfil que (si unimos a lo dicho sobre la sensibilidad religiosa, católica, de Kołakowski, sus críticas al pensamiento marxista y su obligado exilio de Polonia) es el perfil que caracteriza a la inmensa mayoría de 
las referencias cultas que aparecen en el libro de Szczeklik; y que una vez más nos conduce al lúcido pensamiento de Hayden White, ampliamente referido, sobre la ligazón entre la naturaleza de las narraciones, la naturaleza de la cultura y en concreto la cultura del propio narrador, en busca de una identificación cultural que sea el sólido poso moral que ofrezca el texto construido con esos mimbres.

El capítulo «Fronteras y lindes» trata de los virus, de su misteriosa vinculación al genoma y al ADN, y sobre todo de si están vivos, lo que lleva al autor al problema de la definición de la vida y de su frontera. La narración en este capítulo acude a la prosopopeya o fictio personae ${ }^{6}$ para la personificación del virus (Szczeklik, 2012: 230); lo que ayuda a hacer más confusos y misteriosos, inaccesibles al hombre, los límites de la vida. Si no sabemos si el virus es un ser vivo, el hecho de personificarlo figuralmente, de darle un comportamiento figurativo humano («sortea la defensa», «se asegura», «advierte» (Szczeklik, 2012: 231)), ayuda a la ceremonia de la confusión. Todo el capítulo es un cúmulo de expectativas que conducen hacia el fracaso de los intentos científicos por desentrañar cómo surgió la vida, qué hay antes de la vida y qué es la vida. No va más lejos el autor, no hace propuesta personal alguna, no se queda a ninguna carta, y con ello consigue ser más eficaz que si hubiera hecho una propuesta teológica. El silencio se convierte en el ingrediente más persuasivo en este capítulo, en el que se desploman todas las esperanzas humanas racionales y científicas por comprender el origen de la vida.

Conforme avanza el libro, el marco ideológico en el que se mueve el autor queda cada vez más definido. Diríamos que va adensando el grado de identidad cultural. El libro va intensificando la valoración moral. Así, en el capítulo «De la muerte y el morir» vuelve a moverse en los lugares en sombra del desconocimiento médico, en los lugares inexplicables: la muerte súbita, la reanimación, los momentos intermedios; para poner en duda cualquier decisión sobre los estados vegetativos de los pacientes y la posible decisión de una eutanasia activa. Prefiere una vez más pasar a un cúmulo de referencias literarias y pictóricas para hablarnos de la constante meditación humana por la muerte (Szczeklik, 2012: 263-264), del asombro que todavía despierta, para decirnos que sigue siendo un misterio que la ciencia no ha podido desvelar y sugerirnos que no intervengamos de ninguna manera en ese misterio. Todo ese ámbito del desconocimiento, del asombro, lo utiliza de manera pasiva (no hace una argumentación

6. Lausberg la define como consistente en «presentar cosas irracionales como personas que hablan y son capaces de comportase en todo lo demás como corresponde a personas» (Lausberg, 1975: 241). 
explícita, la argumentación queda en el adensamiento de citas con que procura solidificar su valor moral, su identidad y opción cultural), a favor de su opción: la fe, y de una serie de descalificaciones veladas a ciertas actuaciones activas frente a la muerte por parte de los seres humanos, aunque sean médicos.

Todavía queda más claro el género homilético del ensayo en el capítulo «Las ambiciones de Prometeo», donde se aborda el tema de las células madre y el de la clonación, para conducirnos a Prometeo como la imagen mítica de «todos los que han intentado o intentan crear un ser humano de novo» (Szczeklik, 2012: 302). Intentos que lo más que consiguen es simplemente «conocer un fragmento minúsculo de un misterio que solo Dios conoce al completo» (Szczeklik, 2012: 302).

Considero que el momento antes descrito es la culminación del planteamiento doctrinal de Szczeklik; cuando por primera vez expone de manera explícita su pensamiento. Podríamos considerar la frase sobre el conocimiento de Dios como un resumen o una especie de peroratio de todo lo que ha pretendido con las narrativas de los capítulos anteriores. Y en realidad los capítulos subsiguientes, los dos últimos capítulos del libro, «Encadenamiento amoroso» y «En conjunción», parecen un simple epílogo. «Encadenamiento amoroso» incluso parece errático: pasa del amor como enfermedad a los filtros de amor y a un excurso poco justificable sobre la mandrágora, para saltar a la historia de Tristán e Isolda y a otro excurso sobre la música. No hay ya claramente el desarrollo de una idea principal a la que encadenar tanto eslabón erudito, tal y como sucedía en capítulos anteriores. El resultado al que nos conduce, en cualquier caso, es una vez más que en el arte no queremos la racionalización empobrecedora que sin embargo buscamos en las respuestas empíricas de la ciencia. Las personas ambicionamos el encanto del misterio (Szczeklik, 2012: 324). En cuanto al capítulo final, con el recurso del cuadro Goya curado por el doctor Arrieta, propugna la simbiosis (Szczeklik, 2012: 333) entre médico y paciente, ese elemento humano que siempre está presente en este ensayo y que es lo que más le agradecemos sus lectores, que hoy en día lamentamos la pérdida de la humanización en la medicina moderna, pura técnica que trata al paciente como a un mero objeto. Nos alienta ese médico humano que dice a nuestra alma: «No te abandonaré» (Szczeklik, 2012: 360), aunque se nos aparezca con corneta monjil. Lo que nos aterra es que desde su humanidad quiera imponernos nuestra manera de vivir o morir. 


\section{Referencias bibliográficas}

Albaladejo, T. (2013): «Retórica cultural, lenguaje retórico y lenguaje literario», Tonos digital, 25. http://www.um.es/tonosdigital/znum25/secciones/ estudios-03-retorica_cultural.htm

BARThes, R. (1990): La aventura semiológica, Barcelona, Paidós.

Bruner, J. (1991): «The Narrative Construction of Reality», Critical Inquiry, 18/1: 1-21.

CiCerón, M. T. (1976): De inventione, Londres-Cambridge, Mass., Heinemann y Harvard University Press. Traducción en castellano de Marcelino Menéndez y Pelayo en CiCERón, Obras completas, Madrid, Hernando, v. I, 1924. Más reciente traducción en Cicerón, La invención retórica, Madrid, Gredos, 1997. Traducción, introducción y notas de Salvador Núñez.

GEORGAKOPOUlOU, A. (2011): «Narrative» en ZIENKowsKI, J.; J.-O. ÖSTMAN; J. Verschueren (eds.) (2011): Discursive Pragmatics, Ámsterdam, J. Benjamins, 190-207.

Halsall, A. W. (1998): «La Actualidad de la Retórica» en Albaladejo, T.; F. CHICo; E. DEL Río (eds.) (1998): Retórica hoy, Teoría/Crítica, 5: 259-279.

LAUSBERG, H. (1975): Manual de Retórica Literaria, 3 vols., Madrid, Gredos.

LuKács, G. (1975): Teoría de la novela (junto con El alma y las formas), Barcelona, Grijalbo.

OCHS, E. (2000): «Narrativa» en DIJK, T. vAN (compilador) (2000): El discurso como estructura y proceso, Barcelona, Editorial Gedisa, 271-299.

Perelman, Ch.; L. Olbrechts-Tyteca (1989): Tratado de la argumentación. La nueva retórica, Madrid, Gredos.

Pujante, D. (2003): Manual de retórica, Madrid, Castalia.

Quintiliano, M. F. (1970): Institutionis Oratoriae Libri Duodecim, 2 vols., edición de M. Winterbottom, Nueva York, Oxford University Press. Versión castellana Quintiliano, M. F. (1997-2001): Institutionis oratoriae libri XII, 4 vols., traducción de A. Ortega Carmona, Salamanca, Publicaciones Universidad Pontificia.

Searle, J. (1980): Actos de habla, Madrid, Cátedra.

SzCzeKLIK, A. (2010): Catarsis. Sobre el poder curativo de la naturaleza y del arte, Barcelona, Acantilado.

- (2012): Core. Sobre enfermos, enfermedades y la búsqueda del alma de la medicina, Barcelona, Acantilado.

WhiTe, H. (1980): «The Value of Narrativity in the Representation of Reality», Critical Inquiry, 7/1: 5-27. 